\title{
Intraoperative MRI for optimizing electrode placement for deep brain stimulation of the subthalamic nucleus in Parkinson disease
}

\author{
Zhiqiang Cui, MD, ${ }^{1}$ Longsheng Pan, MD, ${ }^{1}$ Huifang Song, MD, ${ }^{2}$ Xin Xu, MD, ${ }^{1}$ Bainan Xu, MD, ${ }^{1} \mathrm{PhD}$, \\ Xinguang Yu, MD, ${ }^{1}$ and Zhipei Ling, MD'1
}

'Department of Neurosurgery, PLA General Hospital, PLA Postgraduate Medical School, Beijing; and 2Department of Neurology, Hebei Province Luan County People's Hospital, Luan County, Hebei Province, China

\begin{abstract}
OBJECTIVE The degree of clinical improvement achieved by deep brain stimulation (DBS) is largely dependent on the accuracy of lead placement. This study reports on the evaluation of intraoperative MRI (iMRI) for adjusting deviated electrodes to the accurate anatomical position during DBS surgery and acute intracranial changes.

METHODS Two hundred and six DBS electrodes were implanted in the subthalamic nucleus (STN) in 110 patients with Parkinson disease. All patients underwent iMRI after implantation to define the accuracy of lead placement. Fifty-six DBS electrode positions in 35 patients deviated from the center of the STN, according to the result of the initial postplacement iMRI scans. Thus, we adjusted the electrode positions for placement in the center of the STN and verified this by means of second or third iMRI scans. Recording was performed in adjusted parameters in the x-, y-, and z-axes.

RESULTS Fifty-six (27\%) of 206 DBS electrodes were adjusted as guided by iMRI. Electrode position was adjusted on the basis of iMRI 62 times. The sum of target coordinate adjustment was $-0.5 \mathrm{~mm}$ in the $\mathrm{x}$-axis, $-4 \mathrm{~mm}$ in the $y$-axis, and $15.5 \mathrm{~mm}$ in the z-axis; the total of distance adjustment was $74.5 \mathrm{~mm}$ in the x-axis, $88 \mathrm{~mm}$ in the y-axis, and $42.5 \mathrm{~mm}$ in the z-axis. After adjustment with the help of iMRI, all electrodes were located in the center of the STN. Intraoperative MRI revealed 2 intraparenchymal hemorrhages in 2 patients, brain shift in all patients, and leads penetrating the lateral ventricle in 3 patients.
\end{abstract}

CONCLUSIONS The iMRI technique can guide surgeons as they adjust deviated electrodes to improve the accuracy of implanting the electrodes into the correct anatomical position. The iMRI technique can also immediately demonstrate acute changes such as hemorrhage and brain shift during DBS surgery.

http://thejns.org/doi/abs/10.3171/2015.1.JNS141534

KEY WORDS intraoperative magnetic resonance imaging; deep brain stimulation; subthalamic nucleus; Parkinson's disease; functional neurosurgery

$\mathrm{D}$ EEP brain stimulation (DBS) is a proven technique for the treatment of Parkinson disease., ${ }^{2,14,23}$ The degree of clinical improvement achieved by DBS is largely dependent on the accuracy of lead placement. ${ }^{3,716}$ As the subthalamic nucleus (STN) is a relatively small structure, estimated at $9 \times 7 \times 5 \mathrm{~mm}, 18,20$ it is important to define the exact location of the electrode being used for stimulation. Various methods have been used to localize the STN, including MRI, brain atlas-imaging fusion for preoperative planning, intraoperative microelectrode recording (MER), intraoperative MRI (iMRI), temporary efficacy during the operation, postoperative MRI, and sus- tained effect during the postoperative period. Typically, a combination of anatomical and physiological methods is used in the localization of the STN.

Electrophysiological recording of the STN can be obtained intraoperatively via microelectrodes. Real-time physiological confirmation of the target has been reported to be particularly useful, especially as an adjunct to current advanced brain imaging techniques. ${ }^{1,21,27}$ Intraoperative neurophysiological and clinical monitoring techniques may improve postoperative efficacy. However, MRI following DBS lead placement is very important. The use of preoperative MRI for accurate target planning is well ac-

ABBREVIATIONS AC = anterior commissure; DBS = deep brain stimulation; iMRI = intraoperative MRI; MER = microelectrode recording; MP-RAGE = magnetizationprepared rapid gradient echo; $\mathrm{PC}=$ posterior commissure; $\mathrm{STN}=$ subthalamic nucleus.

ACCOMPANYING EDITORIAL See pp 59-61. DOI: 10.3171/2015.2.JNS1556.

SUBMITTED July 7, 2014. ACCEPTED January 9, 2015.

INCLUDE WHEN CITING Published online August 14, 2015; DOI: 10.3171/2015.1.JNS141534. 
cepted. Postoperative MRI following DBS lead placement can help to determine the anatomical position of electrodes as well as identifying acute complications. ${ }^{6,15,24,25}$ With the development of neuroimaging, iMRI during DBS surgery offers immediate confirmation of precise lead placement and screening for complications. In the present study, we evaluated the role of iMRI in targeting the STN in patients with Parkinson disease and determined the accuracy of electrode placement.

\section{Methods}

This study was approved by the ethics committee of the PLA General Hospital.

\section{Patients}

Between January 2010 and December 2013, 206 DBS electrodes were implanted in the STN in 110 patients with Parkinson disease (bilateral implantation in 94 patients, unilateral implantation in 18 patients). All patients received iMRI after implantation (before implanting pulse generator) to define the accuracy of lead placement. One hundred and fifty DBS electrode positions were verified in the center of the STN by the first iMRI scan. Fifty-six DBS electrodes positions in 35 patients $(28$ males, 7 females, average age 58 years, range 39-77 years) deviated from the center of the STN according to the initial iMRI scans. Thus, we adjusted electrode positions for placement in the center of the STN and verified this by second or third iMRI scans.

\section{Surgical Procedure}

Using local anesthesia, a stereotactic head frame (Leksell model $\mathrm{F}$ head frame) was placed before stereotactic MRI. MRI was performed for all the patients using 1.5T scanners (Siemens Espree). Imaging was used to identify the anterior commissure (AC), posterior commissure (PC), midcommissural point, and target coordinates. The STN was localized with high-resolution T2-weighted MR images (1.5 T, TR 5500, TE 98; Fig. 1). The anterior and posterior commissures were identified in a midsagittal planning scan. Axial images, $3 \mathrm{~mm}$ thick, were acquired parallel to the AC-PC plane, and coronal images orthogonal to these were then obtained. Planning was performed to determine entry points for a safe electrode trajectory parallel to the long axis of the STN and avoiding blood vessels and the ventricles. The anatomical target coordinates for STN stimulation were $12 \mathrm{~mm}$ lateral, $3 \mathrm{~mm}$ posterior, and $4 \mathrm{~mm}$ inferior to the midpoint of the $\mathrm{AC}-\mathrm{PC}$ line, which were used as an initial guideline only. ${ }^{2}$

The STN was clearly visualized on T2-weighted images. However, the STN morphology exhibited interindividual differences, and the target was adjusted to the center of the STN according to the individual patient's anatomy. Once imaging was completed and the target coordinates were obtained, the patient was returned to the operating room under sterile conditions and local anesthesia. In order to reduce CSF leakage, the neck was flexed to raise the head as far as possible while maintaining airway patency. Scalp incision and bur holes were performed according to the entry points of the planned trajectory coordinates.

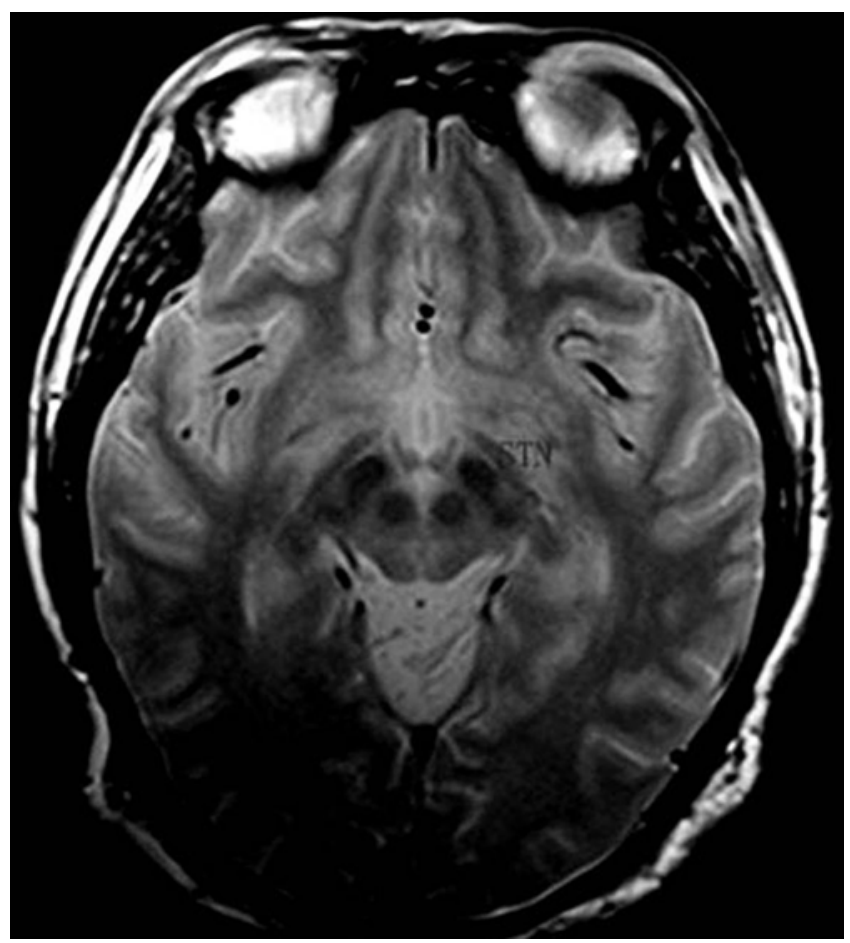

FIG. 1. Axial T2-weighted MR image showing preoperative visualization of the STN.

Refinement of the STN coordinates using intraoperative MER was routinely performed. Single-track MER (intraoperative microelectrode, Medtronic Ltd.) was obtained using the Medtronic Leadpoint neural activity monitoring system. The electrode was advanced with the use of a clinical microdrive (MicroTargeting Drive, FHC, Inc.). The microelectrode was advanced to $8 \mathrm{~mm}$ above the target. During the recording, fibrin sealant was used to cover the bur holes to reduce the loss of CSF. After MER and placement of DBS 3389 electrodes (Medtronic, Ltd.), test stimulation was conducted using a temporary external stimulator (Programmer, 8840). The patient remained awake so that temporary efficacy could be observed and verbal feedback could be obtained to ensure that unwanted adverse effects did not occur. Confirmation of accurate electrode placement was then performed with iMRI.

\section{Intraoperative MRI}

The MRI unit and the operating room were separated by a sliding door, and the MR machine (Siemens Espree, $1.5 \mathrm{~T}$ ) could enter into the operating room via a short track attached to the ceiling. Before iMRI scans, the open MR indicator was fixed in the stereotactic head frame. The MRI parameters for T1-weighted, 3D magnetization-prepared rapid gradient echo (MP-RAGE) were as follows: TE $3.02 \mathrm{msec}$, TR $1650 \mathrm{msec}$, matrix size $256 \times 256$, FOV $260 \times 260 \mathrm{~mm}$, FOV phase $100 \%$, slice thickness $1 \mathrm{~mm}$, 16-cm slab. T2-weighted image parameters were: TE 93 mms, TR $5500 \mathrm{msec}$, matrix size $512 \times 512$, FOV $260 \times$ $260 \mathrm{~mm}$, FOV phase $100 \%$, and slice thickness $3 \mathrm{~mm}$. A technician and MRI physicist completed the MRI scans and analyzed the imaging. If the first intraoperative MRI 
showed the electrodes positioned in the center of the STN and at an appropriate depth, a pulse generator (Medtronic, Inc.) was placed in the chest area under the clavicle. If the initial postplacement iMRI showed that the electrode position deviated from the center of the STN, or that the electrode depth was not appropriate, we measured the deviated distance and adjusted the coordinates. Second and sometimes third MRI scans were performed until the electrodes were located appropriately.

\section{Results}

Thirty-five patients (bilateral implantation in 28 patients, unilateral implantation in 7 patients) received 2 or more iMRI scans (31 patients with 2 iMRI scans, 4 patients with 3 scans). Fifty-six (27\%) of 206 DBS electrodes were adjusted based on iMRI guidance. The total number of electrode position adjustments was 62, with 50 DBS electrodes being adjusted only once, and 6 DBS electrodes requiring a second adjustment (Table 1 ). If we adjusted the coordinate to the right in the $\mathrm{x}$-axis, the value was indicated as negative; if the coordinate was adjusted to the left, the value was indicated as positive. If the coordinate was adjusted in the posterior direction in the y-axis, the value was indicated as negative, while the value was positive if the coordinate was adjusted in the anterior direction. If the coordinate was adjusted in the inferior direction in the $\mathrm{z}$-axis, the value was indicated as negative, while the value was positive if the coordinate was adjusted in the superior direction. The sum of target coordinate adjustments was $-0.5 \mathrm{~mm}$ in the $\mathrm{x}$-axis, $-4 \mathrm{~mm}$ in the $\mathrm{y}$-axis, and $15.5 \mathrm{~mm}$ in the z-axis, with a total distance adjustment of $74.5 \mathrm{~mm}$ in the x-axis, $88 \mathrm{~mm}$ in the $\mathrm{y}$-axis, and $42.5 \mathrm{~mm}$ in the $\mathrm{z}$ axis (Table 2, Fig. 2). Through adjustment with the help of iMRI, all electrodes were ultimately located in the center of the STN (Figs. 3 and 4). Intraoperative MRI revealed 2 intraparenchymal hemorrhages (Fig. 5), one of which was accompanied by obvious mental symptoms. Although fibrin sealant was used to reduce the loss of CSF, differing degrees of posterior brain shift due to intracranial air was identified in all patients (Fig. 6). Electrodes were found to penetrate the lateral ventricle in 3 patients (Fig. 6).

\section{Discussion}

In the present study cohort, we used single-channel MER in the implantation of 206 DBS electrodes. However, 56 DBS electrodes were found to be deviated from the center of the STN at iMRI confirmation. Thus, approximately $27 \%$ of the electrodes required adjustment with the help of iMRI. Huston et al. reported on a cohort of 143 patients who underwent 152 DBS surgeries, including 289 lead placements, utilizing intraoperative 1.5-T MRI. ${ }^{11}$ However, only the scan series, hemorrhage, and brain shift were described in that study, with no information on position adjustment of electrodes or the number of MRI scans. By comparison, the amount of position adjustment was much higher in our cases; we believe that this difference is related to our emphasis on the accurate anatomical position of STN. With respect to intraoperative hemorrhage, we found only 2 intraparenchymal hemorrhages in our cohort, compared with 5 subdural hematomas, 3 subarach- noid hemorrhages, and 1 intraparenchymal hemorrhage in the cohort reported on by Huston et al. ${ }^{11}$

Starr et al. recently reported an innovative DBS procedure that utilizes an intraoperative 1.5-T MRI unit and a skull-mounted aiming device for direct electrode placement into the STN while the patient is within the magnet bore. ${ }^{22}$ In that study, no hemorrhagic complications were observed in 29 patients with Parkinson disease, suggesting that the surgical procedure of DBS implantation is safe. In our experience, iMRI is particularly useful for confirming accurate electrode placement and repositioning if required, as brain shift caused by intracranial air occurred in all of our patients.

In the present cohort, 31 patients received 2 iMRI scans and 4 patients received 3 scans. If the first iMRI scan showed deviation of the electrode position from the center of the STN, or showed that the electrode depth was not appropriate, we measured the deviated distance and adjusted the coordinates. Second and occasionally third iMRI scans were performed until the electrodes were accurately positioned. According to the results of iMRI scans, 35 patients required electrode adjustment, for a total of 62 electrode adjustments (50 DBS electrodes required 1 adjustment, while 6 required 2 adjustments).

We used T1-weighted 3D MP-RAGE sequences for our initial scan, as this sequence used a thin slice thickness (1 $\mathrm{mm}$ ) and was able to show the electrode position in axial, coronal, and sagittal planes. However, the acquisition time for this scan was quite long, and the morphology of the STN was not shown clearly. Thus, we also performed T2weighted imaging to show STN morphology and determine the electrode locations. Note that T2-weighted images cannot show the 3D image, and they provide a slice thickness of $3 \mathrm{~mm}$ (with 1.5-T MRI). Thus, the T1-weighted 3D MP-RAGE and T2-weighted images are complementary, and data from both imaging series are used to guide the adjustment of the electrode direction and depth. Because of the ability to image subarachnoid air or CSF, the T1-weighted MP-RAGE images were able to show different degrees of intracranial air in all patients. The iMRI scans also enabled detection of hemorrhage during the operation. Although Starr et al. reported that FLAIR is sensitive to hemorrhage, ${ }^{22}$ we have found that T1-weighted 3D MP-RAGE and T2-weighted images are suitable.

It is well established that good outcomes of DBS are more likely when the electrode completely penetrates the long axis of the STN. Thus, the electrode track must be as close as possible to the lateral ventricles, without passing through them. In our study, we found that the electrodes penetrated the lateral ventricle in 3 patients; this can create a large deviation of the electrode tip, resulting in inaccurate electrode placement into the STN.

The sum of target coordinate adjustments in the present study was $-0.5 \mathrm{~mm}$ in the $\mathrm{x}$-axis, $-4 \mathrm{~mm}$ in the $\mathrm{y}$-axis, and $15.5 \mathrm{~mm}$ in the z-axis, with a total distance adjustment of $74.5 \mathrm{~mm}$ in the $\mathrm{x}$-axis, $88 \mathrm{~mm}$ in the $\mathrm{y}$-axis, and $42.5 \mathrm{~mm}$ in the z-axis, and an average distance of $1.2 \mathrm{~mm}$ in the $\mathrm{x}$-axis, $1.42 \mathrm{~mm}$ in the y-axis, and $0.69 \mathrm{~mm}$ in the z-axis. In a preliminary review of 6 cases, using a combination of pre- and postoperative MRI by landmark co-registration, Schrader et al. reported an error of $0.5 \mathrm{~mm}$ in the $\mathrm{x}$-axis 
TABLE 1. Findings in 35 patients in whom electrode position was adjusted based on second or third iMRI scans

\begin{tabular}{|c|c|c|c|c|c|c|c|c|c|c|c|}
\hline \multirow{2}{*}{$\begin{array}{l}\text { Case } \\
\text { No. }\end{array}$} & \multirow{2}{*}{$\begin{array}{l}\text { Age } \\
\text { (yrs) }\end{array}$} & \multirow[b]{2}{*}{ Sex } & \multirow{2}{*}{$\begin{array}{c}\text { Duration of } \\
\text { PD (yrs) }\end{array}$} & \multirow{2}{*}{$\begin{array}{l}\text { No. of iMRI } \\
\text { Scans }\end{array}$} & \multirow[b]{2}{*}{ Side } & \multicolumn{3}{|c|}{ Left } & \multicolumn{3}{|c|}{ Right } \\
\hline & & & & & & X-Axis & Y-Axis & Z-Axis & X-Axis & Y-Axis & Z-Axis \\
\hline 1 & 75 & M & 8 & 2 & $\mathrm{~L}$ & -2.5 & -3 & 0 & - & - & - \\
\hline 2 & 54 & $M$ & 4 & 2 & L & 1.5 & -1.5 & 0 & - & - & - \\
\hline 3 & 39 & M & 3 & 2 & L & 2 & -1 & 0 & - & - & - \\
\hline 4 & 49 & $M$ & 20 & 2 & L & 0 & -3 & 0 & - & - & - \\
\hline 5 & 63 & $M$ & 7 & 2 & $R$ & - & - & - & -1 & 1 & 1.5 \\
\hline 6 & 60 & M & 3 & 2 & $\mathrm{R}$ & - & - & - & 0 & -1.5 & 0 \\
\hline 7 & 65 & M & 3 & 2 & $\mathrm{R}$ & - & - & - & -2.5 & 0 & 0 \\
\hline 8 & 70 & $\mathrm{~F}$ & 2 & 2 & B & 0 & -1.5 & 0 & 0 & -1.5 & 0 \\
\hline 9 & 50 & $\mathrm{~F}$ & 2 & 2 & B & 2 & -1 & 0 & 2 & 0 & 0 \\
\hline 10 & 69 & $\mathrm{~F}$ & 3 & 2 & B & 3 & 0 & 2 & 3 & 0 & -1.5 \\
\hline 11 & 75 & $M$ & 2 & 2 & B & 0 & 2 & -2 & 0 & 6 & 0 \\
\hline 12 & 67 & $M$ & 3 & 2 & B & 0 & 1.5 & 0 & 0 & 1.5 & 0 \\
\hline 13 & 52 & $M$ & 4 & 2 & B & 0 & 0 & 2 & 0 & -1.5 & 0 \\
\hline 14 & 47 & $\mathrm{~F}$ & 8 & 2 & B & -2 & 0 & 0 & 0 & 0 & 2 \\
\hline 15 & 63 & $M$ & 3 & 2 & B & 4 & 0 & 0 & 2 & 0 & 0 \\
\hline 16 & 53 & M & 4 & 2 & B & 0 & 1 & 0 & 1.5 & 2 & 0 \\
\hline 17 & 59 & $M$ & 8 & 2 & B & 0 & 0 & 0 & 1.5 & 0 & 0 \\
\hline 18 & 61 & $M$ & 13 & 2 & B & -1.5 & -2 & 0 & 0 & -2 & 0 \\
\hline 19 & 64 & $M$ & 10 & 2 & B & 1 & 1 & -2 & -1 & 1 & 2.5 \\
\hline 20 & 77 & $M$ & 10 & 2 & B & 0 & 3 & 0 & 0 & 5 & 0 \\
\hline 21 & 61 & $M$ & 10 & 2 & B & 2 & -3 & 0 & 0 & 0 & 0 \\
\hline 22 & 44 & $\mathrm{M}$ & 9 & 2 & B & 0 & 0 & 0 & 0 & -2 & 3 \\
\hline 23 & 56 & $M$ & 10 & 2 & B & 0 & 0 & 0 & -1 & -2.5 & 0 \\
\hline 24 & 60 & $\mathrm{~F}$ & 11 & 2 & B & 0 & -2.5 & -2 & 0 & -3 & 0 \\
\hline 25 & 56 & $\mathrm{~F}$ & 10 & 2 & B & 0 & 0 & 0 & -2 & 2 & 0 \\
\hline 26 & 45 & $M$ & 3 & 2 & B & 0 & 0 & 3 & 0 & 0 & 5 \\
\hline 27 & 43 & $M$ & 5 & 2 & B & 0 & 0 & 0 & -1.5 & 1.5 & -3 \\
\hline 28 & 59 & $\mathrm{~F}$ & 8 & 2 & B & -1 & -2 & 0 & -1.5 & -2 & 0 \\
\hline 29 & 58 & M & 9 & 2 & B & 2.5 & -3 & 0 & 0 & 0 & 4 \\
\hline 30 & 59 & $M$ & 13 & 2 & B & 2 & 0 & 0 & 2 & 0 & 0 \\
\hline 31 & 50 & $M$ & 11 & 2 & B & 0 & 0 & 0 & -2.5 & 1 & 0 \\
\hline \multirow[t]{2}{*}{$32^{*}$} & 59 & $M$ & 7 & 3 & B & 1.5 & 0 & 0 & 0 & 2.5 & 0 \\
\hline & & & & & & 1.5 & 5 & -3 & 0 & 2.5 & 0 \\
\hline \multirow[t]{2}{*}{$33^{*}$} & 71 & M & 23 & 3 & B & -3 & 0 & 0 & -3 & 0 & 0 \\
\hline & & & & & & -3.5 & 0 & 0 & -3.5 & 0 & 0 \\
\hline \multirow[t]{2}{*}{$34^{*}$} & 71 & M & 11 & 3 & B & 2 & 0 & 0 & -1.5 & 3 & 0 \\
\hline & & & & & & 2 & 0 & 0 & -1.5 & 2 & 0 \\
\hline \multirow[t]{2}{*}{$35^{*}$} & 77 & M & 4 & 3 & B & 0 & -1 & 2 & 0 & -1.5 & 0 \\
\hline & & & & & & 0 & -2 & 2 & -1.5 & -2 & 0 \\
\hline
\end{tabular}

$B=$ both; $L=$ left; $P D=$ Parkinson disease $; R=$ right; - = no adjustment.

* Indicates cases in which 3 iMRI scans were performed.

and $2 \mathrm{~mm}$ in the z-axis. ${ }^{21}$ Hamid et al. also reported that the distance from the center of the electrode artifact to the final target used after electrophysiological recording on the fused images was $0.48 \mathrm{~mm}, 0.69 \mathrm{~mm}$, and $2.9 \mathrm{~mm}$ in the $\mathrm{x}-, \mathrm{y}-$, and $\mathrm{z}$-axes, respectively. ${ }^{8}$ In our cohort, the average distance in the $\mathrm{y}$-axis was $1.42 \mathrm{~mm}$, which we consider related to intraoperative settling or posterior brain shift due to CSF leakage. The z-axis deviation may be related to the fixation of the electrodes, such that when we used a snap ring (not Medtronic's StimLoc lead anchoring device), the electrodes were pushed into a position lower than the target; this is consistent with data from Hamid et al. ${ }^{8}$ The deviation in the $\mathrm{x}$-axis may relate to attempts to deliberately avoid the lateral ventricle. There were very 
TABLE 2. The direction and distance adjustment of target coordinates in the $x-, y-$, and $z$-axes in 62 DBS electrode positions*

\begin{tabular}{cccc}
\hline & \multicolumn{3}{c}{ Value in Millimeters } \\
\cline { 2 - 4 } Coordinate & $\begin{array}{c}\text { Sum of } \\
\text { Adjustments }\end{array}$ & $\begin{array}{c}\text { Total } \\
\text { Distance }\end{array}$ & $\begin{array}{c}\text { Average } \\
\text { Distance }\end{array}$ \\
\hline $\mathrm{X}$ & -0.5 & 74.5 & 1.20 \\
\hline $\mathrm{Y}$ & -4 & 88 & 1.42 \\
\hline $\mathrm{Z}$ & 15.5 & 42.5 & 0.69 \\
\hline
\end{tabular}

* Total distance refers to the sum of the absolute values of the deviated distances (e.g., $|-\mathrm{X} 1|+|\mathrm{X} 2|+|-\mathrm{X} 3|+|-\mathrm{X} 4|+\ldots . . .|\mathrm{Xn}|)$. Sum of adjustments refers to the sum of the positive and negative deviation values, the sum of target coordinate adjustments (e.g., $[-\mathrm{X} 1]+[\mathrm{X} 2]+[-\mathrm{X} 3]+[-\mathrm{X} 4]+\ldots \ldots . . \mathrm{Xn}])$.

few operational errors in our series; we concluded that the possible reasons for electrode deviation include the following. 1) The localization of the STN with CT, MRI, and preoperative planning system may have deviated from the actual target. 2) Leakage of CSF may have led to posterior brain shift. 3) When the electrodes were penetrating the lateral ventricle, the difference in tissue strength between the cerebral parenchyma and ependyma may have resulted in the electrode shifting to the midline. Even when typical electrophysiology is recorded by MER, the electrodes may deviate from the actual target during implantation. Poor stability and long-term shift are also possible. 4) The distance is $3 \mathrm{~cm}$ between the needle catheter front end and the target. Thus, the process of implanting the electrode is likely to result in deviation from the target due to the distance $(3 \mathrm{~cm})$ between the distal end of the needle catheter and the target (Medtronic Single Channel). 5) There may have been stereotactic instrument system errors.

As the STN is a relatively small structure (estimated at $9 \times 7 \times 5 \mathrm{~mm}),{ }^{18,20}$ various techniques have been used to verify lead location and accuracy of DBS electrode placement. Intraoperative MER was reported to improve the target localization during stereotactic surgery. ${ }^{4,13,17}$ However, this technique provides electrical activity recordings in different brain areas, and it is difficult to determine whether such recording has a positive effect on the clinical outcome of DBS treatment. ${ }^{9,10}$ Further, there is evidence of side effects for both MER and procedures guided without MER, including higher rates of complications such as intracerebral hematoma. ${ }^{5,10}$ Patel et al. also reported that the use of microelectrodes prolongs the operating time, which may increase the risk of infection. ${ }^{19}$ The risk of brain shift because of CSF leak during surgery is also increased, making target localization more difficult. Furthermore, this technique exposes patients to many hours of surgery while awake, which can be very distressing for Parkinson disease patients in an "off" state. As such, the usefulness and requirements for electrophysiology remain controversial.

Good outcomes have been previously reported for DBS implantation without intraoperative recording, ${ }^{26}$ where
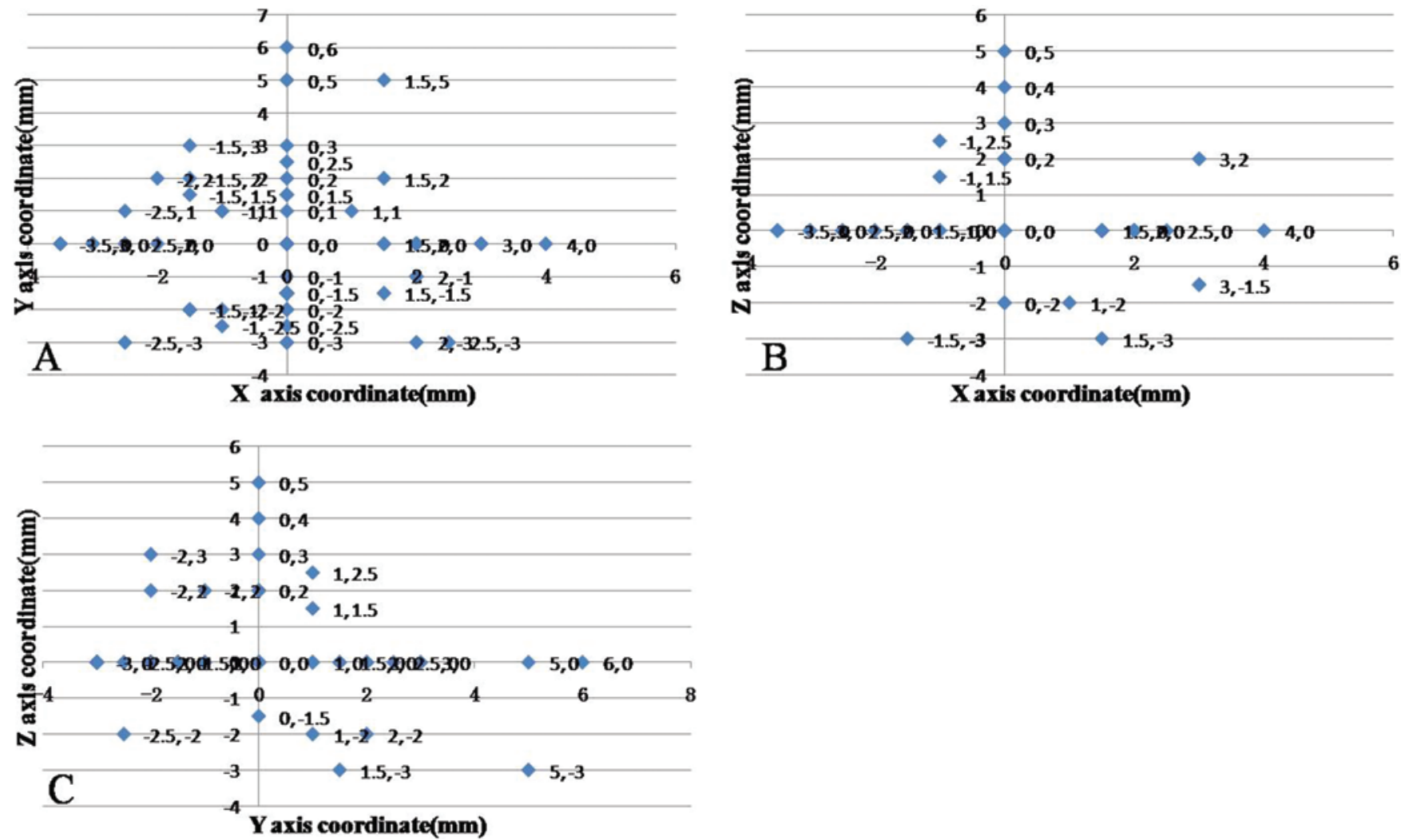

$\mathbf{X}$ axis coordinate(mm)

FIG. 2. The value adjustment of target coordinates in the axial ( $x$ - and $y$-axes, $A)$, coronal ( $x$ - and $z$-axes, $B$ ), and sagittal ( $y$ - and z-axes, $\mathbf{C}$ ) planes in 35 patients. Figure is available in color online only. 


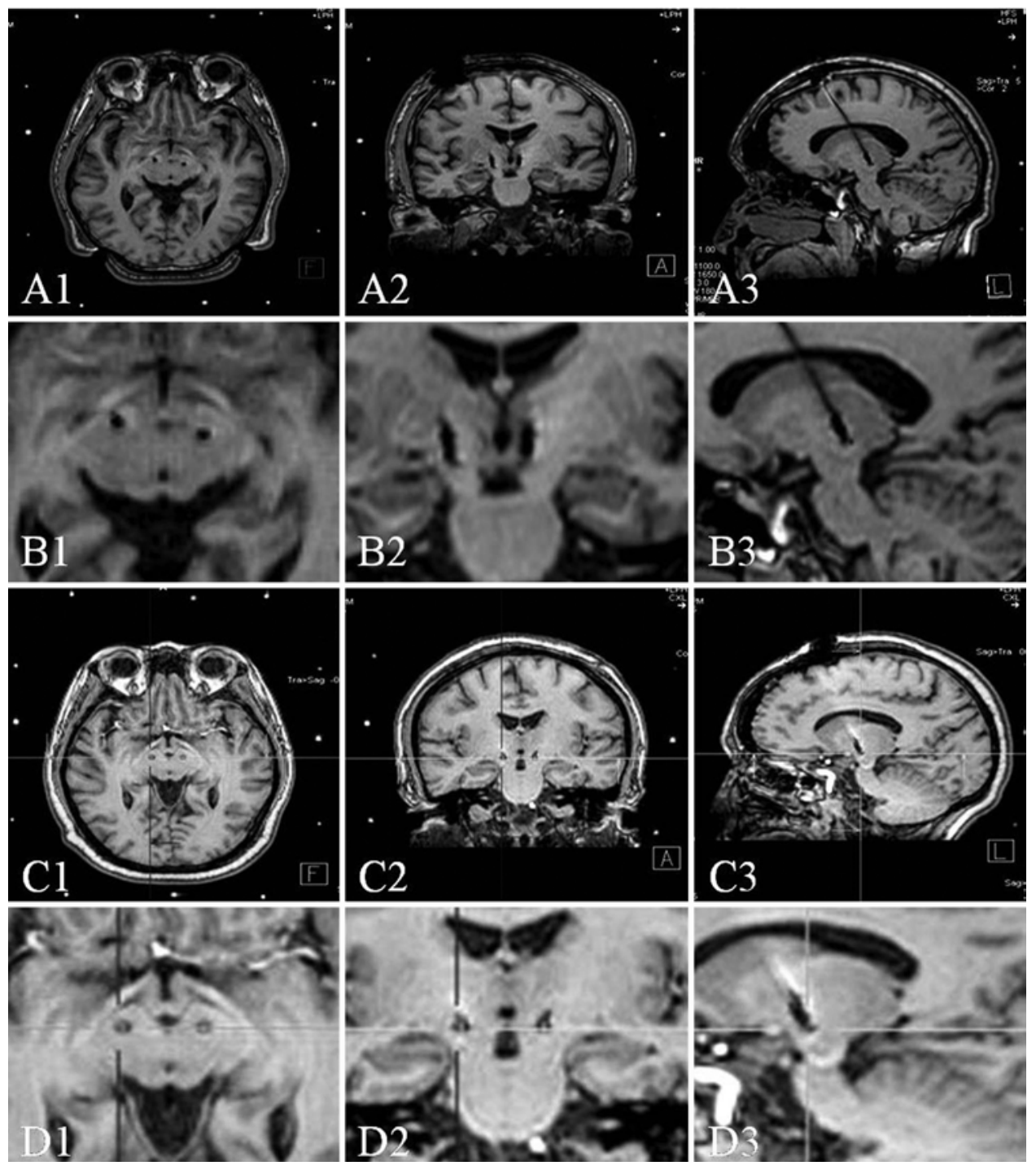

FIG. 3. Intraoperative axial, coronal, and sagittal T1-weighted MR images (with open MR indicator) obtained in a representative case in which iMRI was used to improve positioning of the DBS electrodes. These images in the first 2 rows (A1-B3) were obtained in a first iMRI scan, which showed that the bilateral DBS electrode positions were deviated from the center of the STN to the right. According to the results of the first iMRI scan, the DBS electrodes positions were adjusted, and were verified in the center of the STN by the second iMRI scan (C1-D3). The images in rows B and D are closer views of the region of interest in the corresponding images in rows $A$ and $C$, respectively. Figure is available in color online only.
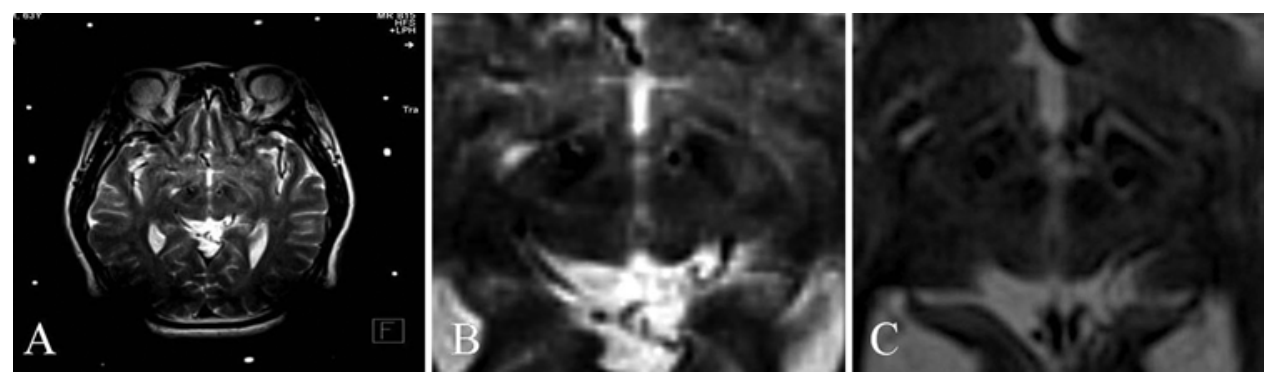

FIG. 4. Intraoperative axial T2-weighted MR-weighted images (with open MR indicator) obtained in a representative case in which iMRI was used to improve positioning of the DBS electrodes. The first iMRI scan (A and B) showed that the bilateral DBS electrode positions were deviated from the center of STN to the right. According to the results of the first iMRI, the DBS electrode positions were adjusted, and were verified in the center of the STN by the second iMRI scan (C). 

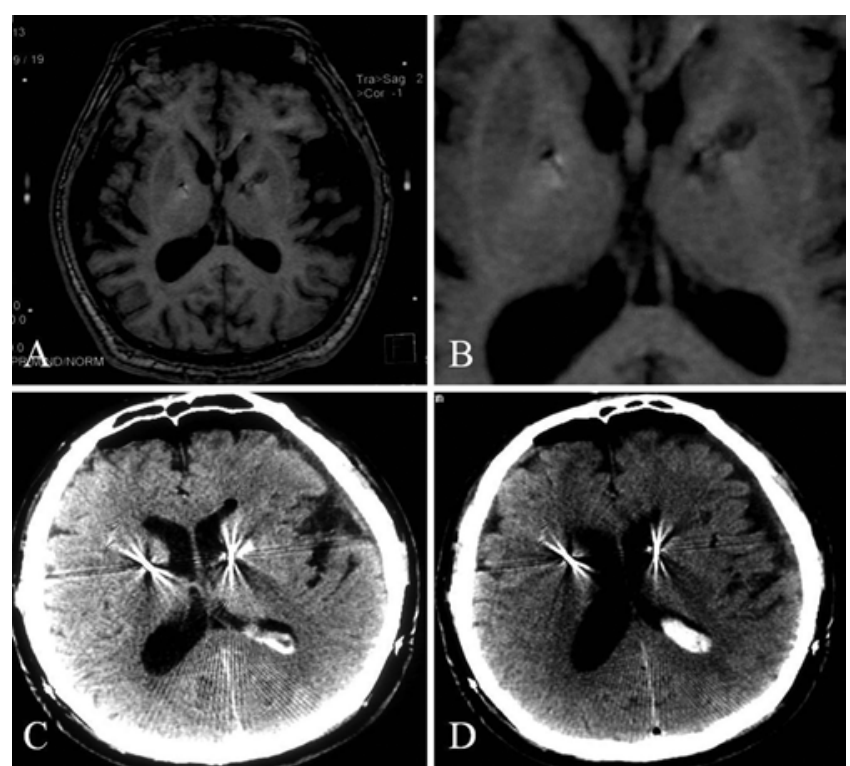

FIG. 5. Images obtained in one of the 2 patients who experienced intraparenchymal hemorrhage during the operation. A and B: Axial T1weighted MR image (A) and enlargement of region of interest (B) showing a small hematoma in the left basal ganglia and anterior accumulation of CSF, and consequent posterior shift in position of the brain within the cranium (more apparent in the left hemisphere). C and D: Axial images from the postoperative CT scan performed the day after the operation showing the electrode lead penetrating the anterior horn of the left lateral ventricle and a hematoma from the lead tract in the posterior horn.

projection of electrode artifacts from postoperative T1weighted MRI onto the STN, as visualized by preoperative T2-weighted MRI, provided direct evidence for electrode placement into the STN. With this method, the position of the electrode can be assessed relative to the MRI-defined anatomy of the STN in individual patients. Patel et al. also reported that a predominantly anatomical MRI-directed technique with macrostimulation can be used safely and effectively without the additional need for intraoperative MER, and that this procedure provides an efficient use of operating time and obviates the necessary costs of MER.$^{19}$

Before an operation, the targeting of the STN can be planned according to MRI visualization. However, stereotactic frame system error, shifting of the brain due to CSF leakage and other reasons can result in electrode position deviation. Updated iMRI data and guidance of microelectrode and macroelectrode placement would help to improve the accuracy of the electrode position. Intraoperative MRI is a well-established technique that allows a neurosurgeon to update neuronavigation data online-to evaluate the extent of tumor resection or correct for intraoperative brain shift, for example. This allows the surgeon to modify the surgical strategy if necessary, to guide instruments to the lesion, and to evaluate presence of intraoperative complications at the end of surgery. ${ }^{12}$ At present, the iMRI technique has been mostly applied in neurosurgical resection of tumors, rather than in implantation of DBS electrodes. However, in the present study cohort of patients with Parkinson disease undergoing DBS surgery, all of the patients received iMRI at least once. In this study, we found iMRI helpful for anatomical target local-
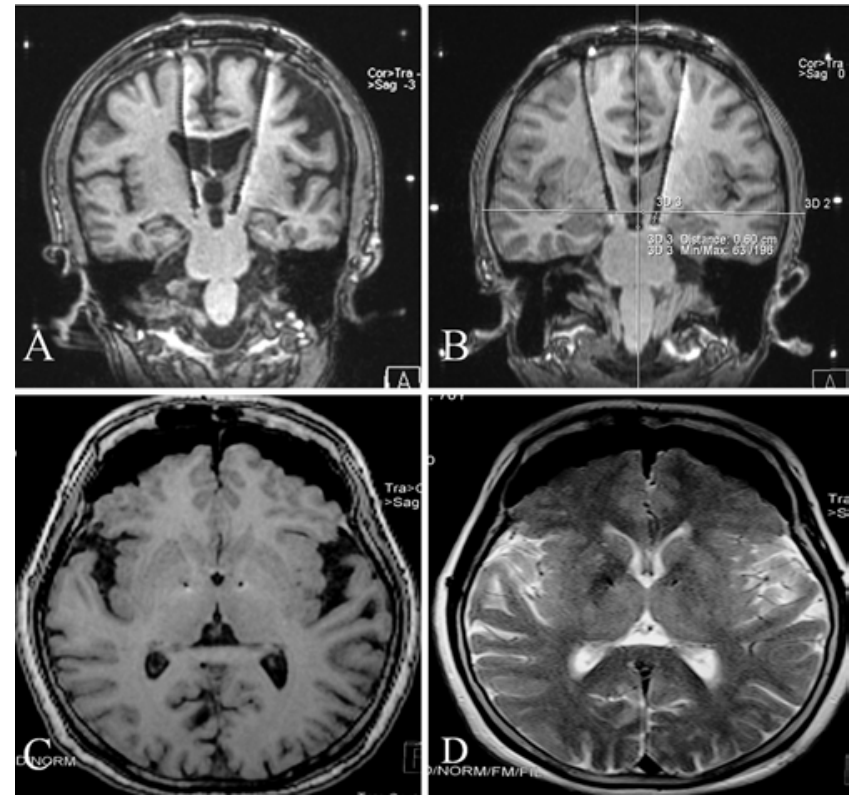

FIG. 6. Case of posterior brain shift due to penetration of the lateral ventricle. A: T1-weighted MR image showing the electrode lead penetrating the right lateral ventricle. B: Coronal T1-weighted MR image showing the difference in depth of the bilateral electrodes. C and D: Axial T1-weighted (C) and T2-weighted (D) images showing brain shift due to CSF leakage.

ization and target adjustment of STN. These adjustments confirmed that for some patients, the DBS target as determined by preoperative planning and/or the target achieved in the initial placement of the electrodes was inconsistent with the real target. Our experience is that in DBS surgery, the use of iMRI identifies intraoperative hemorrhage and provides a clear indication of the location and amount of hemorrhage, when present; clearly shows the extent of bilateral frontal pneumocephalus; allows assessment of CSF loss (frontal subarachnoid space, the lateral ventricles and the third ventricle), and thus the extent of posterior brain shift; provides the precise location of electrode contacts and the lead tract; and guides the adjustment of coordinates in cases of deviation.

It is controversial whether iMRI or MER is the superior method for localizing STN, but we believe that any method that improves anatomical targeting will be useful for DBS. Both MER and iMRI were used to pinpoint the STN from distinct electrophysiological and anatomical points of view. They are excellent complementary approaches.

\section{Conclusions}

The use of iMRI allows surgeons to assess and adjust the position of DBS electrodes so as to better achieve placement in the center of the STN, and can also provide information on acute changes such as the hemorrhage and brain shift during DBS surgery.

\section{Acknowledgments}

We thank the members of the Department of Neurosurgery, PLA General Hospital (Jun Zhang, MD; Zheng-Hui Sun, MD; Jin- 
Li Jiang, MD; Xiao-Dong Ma, MD; Xiao-Lei Chen, MD, PhD; and $\mathrm{Bo}-\mathrm{Bu}, \mathrm{MD})$ for their collaborative support.

\section{References}

1. Bejjani BP, Dormont D, Pidoux B, Yelnik J, Damier P, Arnulf I, et al: Bilateral subthalamic stimulation for Parkinson's disease by using three-dimensional stereotactic magnetic resonance imaging and electrophysiological guidance. J Neurosurg 92:615-625, 2000

2. Benabid AL, Benazzouz A, Hoffmann D, Limousin P, Krack P, Pollak P: Long-term electrical inhibition of deep brain targets in movement disorders. Mov Disord 13 (Suppl 3):119-125, 1998

3. Benabid AL, Pollack P, Benazzouz A: Grenoble guidelines for deep brain stimulation, in First European Symposium on Stimulation in Parkinson Disease. Grenoble, France: Universite Joseph Fourier de Grenoble, 1998

4. Benazzouz A, Breit S, Koudsie A, Pollak P, Krack P, Benabid AL: Intraoperative microrecordings of the subthalamic nucleus in Parkinson's disease. Mov Disord 17 (Suppl 3):S145S149, 2002

5. Carroll CB, Scott R, Davies LE, Aziz T: The pallidotomy debate. Br J Neurosurg 12:146-150, 1998

6. Chhabra V, Sung E, Mewes K, Bakay RA, Abosch A, Gross RE: Safety of magnetic resonance imaging of deep brain stimulator systems: a serial imaging and clinical retrospective study. J Neurosurg 112:497-502, 2010

7. Cuny E, Guehl D, Burbaud P, Gross C, Dousset V, Rougier A: Lack of agreement between direct magnetic resonance imaging and statistical determination of a subthalamic target: the role of electrophysiological guidance. J Neurosurg 97:591-597, 2002

8. Hamid NA, Mitchell RD, Mocroft P, Westby GW, Milner J, Pall H: Targeting the subthalamic nucleus for deep brain stimulation: technical approach and fusion of pre- and postoperative MR images to define accuracy of lead placement. J Neurol Neurosurg Psychiatry 76:409-414, 2005

9. Hariz MI: Safety and risk of microelectrode recording in surgery for movement disorders. Stereotact Funct Neurosurg 78:146-157, 2002

10. Hariz MI, Fodstad H: Do microelectrode techniques increase accuracy or decrease risks in pallidotomy and deep brain stimulation? A critical review of the literature. Stereotact Funct Neurosurg 72:157-169, 1999

11. Huston OO, Watson RE, Bernstein MA, McGee KP, Stead $\mathrm{SM}$, Gorman DA, et al: Intraoperative magnetic resonance imaging findings during deep brain stimulation surgery. $\mathbf{J}$ Neurosurg 115:852-857, 2011

12. Keles GE: Intracranial neuronavigation with intraoperative magnetic resonance imaging. Curr Opin Neurol 17:497500, 2004

13. Krack P, Batir A, Van Blercom N, Chabardes S, Fraix V, Ardouin $C$, et al: Five-year follow-up of bilateral stimulation of the subthalamic nucleus in advanced Parkinson's disease. $\mathbf{N}$ Engl J Med 349:1925-1934, 2003

14. Krack P, Hamel W, Mehdorn HM, Deuschl G: Surgical treatment of Parkinson's disease. Curr Opin Neurol 12:417-425, 1999

15. Larson PS, Richardson RM, Starr PA, Martin AJ: Magnetic resonance imaging of implanted deep brain stimulators: experience in a large series. Stereotact Funct Neurosurg 86:92-100, 2008
16. Limousin P, Pollak P, Benazzouz A, Hoffmann D, Le Bas JF, Broussolle E, et al: Effect of parkinsonian signs and symptoms of bilateral subthalamic nucleus stimulation. Lancet 345:91-95, 1995

17. Lozano AM, Hutchison WD, Dostrovsky JO: Microelectrode monitoring of cortical and subcortical structures during stereotactic surgery. Acta Neurochir Suppl 64:30-34, 1995

18. Morel A, Magnin M, Jeanmonod D: Multiarchitectonic and stereotactic atlas of the human thalamus. J Comp Neurol 387:588-630, 1997

19. Patel NK, Plaha P, O’Sullivan K, McCarter R, Heywood P, Gill SS: MRI directed bilateral stimulation of the subthalamic nucleus in patients with Parkinson's disease. J Neurol Neurosurg Psychiatry 74:1631-1637, 2003

20. Schaltenbrand G, Wahren W: Atlas for Stereotaxy of the Human Brain. New York: Thieme, 1977

21. Schrader B, Hamel W, Weinert D, Mehdorn HM: Documentation of electrode localization. Mov Disord 17 (Suppl 3):S167-S174, 2002

22. Starr PA, Martin AJ, Ostrem JL, Talke P, Levesque N, Larson PS: Subthalamic nucleus deep brain stimulator placement using high-field interventional magnetic resonance imaging and a skull-mounted aiming device: technique and application accuracy. J Neurosurg 112:479-490, 2010

23. Starr PA, Vitek JL, Bakay RA: Ablative surgery and deep brain stimulation for Parkinson's disease. Neurosurgery 43:989-1015, 1998

24. Tagliati M, Jankovic J, Pagan F, Susatia F, Isaias IU, Okun MS: Safety of MRI in patients with implanted deep brain stimulation devices. Neuroimage 47 (Suppl 2):T53-T57, 2009

25. US Federal Food and Drug Administration: FDA Public Health Notification: MRI-caused injuries in patients with implanted neurological stimulators. (http://www.fda.gov/ MedicalDevices/Safety/AlertsandNotices/PublicHealthNotifications/ucm062125.htm) [Accessed May 27, 2015]

26. Voges J, Volkmann J, Allert N, Lehrke R, Koulousakis A, Freund $\mathrm{HJ}$, et al: Bilateral high-frequency stimulation in the subthalamic nucleus for the treatment of Parkinson disease: correlation of therapeutic effect with anatomical electrode position. J Neurosurg 96:269-279, 2002

27. Zonenshayn M, Rezai AR, Mogilner AY, Beric A, Sterio D, Kelly PJ: Comparison of anatomic and neurophysiological methods for subthalamic nucleus targeting. Neurosurgery 47:282-294, 2000

\section{Disclosure}

The authors report that they have no personal, financial, or institutional interest in any of the drugs, materials, or devices described in this article.

\section{Author Contributions}

Conception and design: Ling. Acquisition of data: Pan, X Xu. Analysis and interpretation of data: Cui. Drafting the article: Cui. Critically revising the article: B Xu. Reviewed submitted version of manuscript: Yu. Statistical analysis: Song.

\section{Correspondence}

Zhipei Ling, Department of Neurosurgery, Chinese PLA General Hospital, No. 28, Fuxing Rd., Haidian District, Beijing 100853, China. email: 1zp301hos@126.com. 